\title{
Review \\ Gallstone Disease, Obesity and the Firmicutes/Bacteroidetes Ratio as a Possible Biomarker of Gut Dysbiosis
}

\author{
Irina N. Grigor'eva
}

Citation: Grigor'eva, I.N. Gallstone Disease, Obesity and the Firmicutes/ Bacteroidetes Ratio as a Possible Biomarker of Gut Dysbiosis. J. Pers. Med. 2021, 11, 13. https://dx.doi. org/10.3390/jpm11010013

Received: 14 November 2020 Accepted: 22 December 2020 Published: 25 December 2020

Publisher's Note: MDPI stays neutral with regard to jurisdictional claims in published maps and institutional affiliations.

Copyright: (c) 2020 by the author. Licensee MDPI, Basel, Switzerland. This article is an open access article distributed under the terms and conditions of the Creative Commons Attribution (CC BY) license (https: / / creativecommons.org/ licenses/by/4.0/).
Laboratory of Gastroenterology, Research Institute of Internal and Preventive Medicine-Branch of The Federal Research Center Institute of Cytology and Genetics of Siberian Branch of Russian Academy of Sciences, Novosibirsk 630089, Russia; niitpm.office@gmail.com; Tel.: +7-9137520702

\begin{abstract}
Obesity is a major risk factor for developing gallstone disease (GSD). Previous studies have shown that obesity is associated with an elevated Firmicutes/Bacteroidetes ratio in the gut microbiota. These findings suggest that the development of GSD may be related to gut dysbiosis. This review presents and summarizes the recent findings of studies on the gut microbiota in patients with GSD. Most of the studies on the gut microbiota in patients with GSD have shown a significant increase in the phyla Firmicutes (Lactobacillaceae family, genera Clostridium, Ruminococcus, Veillonella, Blautia, Dorea, Anaerostipes, and Oscillospira), Actinobacteria (Bifidobacterium genus), Proteobacteria, Bacteroidetes (genera Bacteroides, Prevotella, and Fusobacterium) and a significant decrease in the phyla Bacteroidetes (family Muribaculaceae, and genera Bacteroides, Prevotella, Alistipes, Paludibacter, Barnesiella), Firmicutes (genera Faecalibacterium, Eubacterium, Lachnospira, and Roseburia), Actinobacteria (Bifidobacterium genus), and Proteobacteria (Desulfovibrio genus). The influence of GSD on microbial diversity is not clear. Some studies report that GSD reduces microbial diversity in the bile, whereas others suggest the increase in microbial diversity in the bile of patients with GSD. The phyla Proteobacteria (especially family Enterobacteriaceae) and Firmicutes (Enterococcus genus) are most commonly detected in the bile of patients with GSD. On the other hand, the composition of bile microbiota in patients with GSD shows considerable inter-individual variability. The impact of GSD on the Firmicutes / Bacteroidetes ratio is unclear and reports are contradictory. For this reason, it should be stated that the results of reviewed studies do not allow for drawing unequivocal conclusions regarding the relationship between GSD and the Firmicutes / Bacteroidetes ratio in the microbiota.
\end{abstract}

Keywords: Firmicutes; Bacteroidetes; gut microbiota; bile microbiota; gallstone patients

\section{Introduction}

Obesity is defined as excessive fat accumulation that may impair health; obesity is a result of an imbalance between energy intake and expenditure [1,2]. Today obesity has become pandemic; about 1.9 billion people on the planet are overweight: overall, about $13 \%$ of the world's adult populations (11\% of men and $15 \%$ of women) were obese in 2016 [3]. The World Health Organization (WHO) estimated that nearly 2.8 million deaths annually are a consequence of overweight and obesity-associated conditions [3], such as atherosclerosis, diabetes, gallstone disease (GSD), etc. [4-6].

GSD is a common benign gastrointestinal disease affecting $10-15 \%$ of adults around the world that greatly contributes to health care costs [7-10]. Risk factors of the GSD are age, female sex, obesity, insulin resistance, physical inactivity, genetic background, dietary factors (high carbohydrate, high-calorie intake), dyslipoproteinaemia, certain diseases (such as diabetes mellitus, nonalcoholic fatty liver disease (NAFLD), hypertension, and cardiovascular disease) and medications (hormone replacement therapy, fibrates, etc.), social and economic issues, fertility, and intestinal factors (with increased absorption of cholesterol, slow intestinal motility, and dysbiosis) [7-10]. Obesity is a major risk factor for developing GSD [9-12] because it is accompanied by increased synthesis and excretion of cholesterol into bile [13], wherein the amount of cholesterol produced is 
directly proportional to being overweight [11].Obesity is regarded as an inflammatory condition [14]. Inflammation may be the potential link between insulin resistance and gallstones [15]. Insulin resistance is considered a risk factor for GSD, as it may lead to excess biliary cholesterol production and saturation $[16,17]$ and alone may be responsible for gallbladder dysmotility [18]. However, the absence of a relationship between body mass index (BMI) and GSD had been reported in several epidemiologic studies [7,8,19]. The possible pathogenesis for the close association between obesity and GSD iscomplex and not fully understood.

A significant relationship exists among food intake, energy balance and gut peptides that are secreted from gastrointestinal enteroendocrine cells, such as ghrelin, leptin, glucagon-like peptide-1, cholecystokinin (CCK), peptide tyrosine tyrosine (PYY), and serotonin [20]. Let's focus on two of them. Ghrelin, an orexigenic peptidyl hormone secreted from the stomach, was discovered in 1999 and is associated with feeding and energy balance [21]. Ghrelin increases appetite and energy expenditure and promotes the use of carbohydrates as a source of fuel at the same time as sparing fat [22]. The development of resistance to leptin andghrelin, hormones that are crucial for the neuroendocrine control of energy homeostasis, is a hallmark ofobesity [23]. The impact of acyl-ghrelin on glucose metabolism and lipid homeostasis may allow for novel preventative or early intervention therapeutic strategies to treat obesity-related type 2 diabetes and associated metabolic dysfunction [24]. There were no differences for total bile acids, insulin, ghrelin, and glucosedependent insulinotropic polypeptide between patients with GSD and the control group without gallstones [25]. Mendez-Sanchez et al. (2006) found an inverse correlation of serum ghrelin levels and theprevalence of GSD in alogistic regression analysis (OR $=0.27$, $95 \%$ CI 0.09-0.82, $p=0.02$ ) [26]. Authors suggest that serum ghrelin concentrations are associated with a protective effect of GSD and this is related to a motilin-like effect of ghrelin on the gallbladder motility. However, themedian of serum ghrelin values did not show a difference between the patients and controls (660 vs. $682 \mathrm{ng} / \mathrm{L}$ ) [26].

Leptin is associated with obesity: although it should reduce food intake and body weight, in obese patientsthe serum leptin levels are higher than in the lean individuals and do not manage reducing their food intake [27]. Insulin and leptin play an important role in the development of prediabetes and NAFLD, which is a risk factor for GSD. There could be the following pathogenic links: obesity promotes insulin resistance; high levels of insulin increase leptin levels; leptin cannot lead to decreased insulin levels and decreased appetite because of leptin resistance in the nervous system and the adipose tissue; and high levels of leptin promote hepatic steatosis which in turn increases insulin resistance [27]. Positive correlations between serum leptin and BMI, CCK, total cholesterol, and insulin were found in the gallstone group [28].

Gut microbiota can regulate levels of these gut peptides and thus regulate intestinal metabolism via the microbiota-gut-brain axis [20]. Serum ghrelin levels were negatively correlated with Bifidobacterium, Lactobacillus and B. coccoides-Eubacterium rectale, and positively correlated with Bacteroides and Prevotella [29]. Leptin was negatively correlated with Clostridium, Bacteroides and Prevotella, and positively correlated with Bifidobacterium and Lactobacillus [29].The results of the studies on the relationship between GSD, obesity, and incretin hormones remain controversial.

GSD and obesity have similar prevalence [10]. Most of the above risk factors are common to GSD and obesity. Despite the increasing number of scientific publications on the gut microbiota in obesity, there is a lack of studies that assess the gut microbiota in GSD. Research on this topic is limited and mainly focused on the study of certain genera and species of microorganisms, but not the Firmicutes/Bacteroidetes ratio. Many studies have shown that, in humans, obesity is associated with an increased Firmicutes/Bacteroidetes ratio in comparison with lean or "healthy obese" individuals [1,2,30-42]. This review presents and summarizes the recent findings of studies on the gut microbiota in patients with GSD regarding the Firmicutes/Bacteroidetes ratio, as a possible biomarker of obesity, given that obesity is a key risk factor for GSD. 


\section{The Gut Microbiome and Its Functions}

Bacteria emerged 3.8 billion ago [43]. There are about 10 trillion human cells in the human body and about 100 trillion cells outside and inside our bodies being of microbial origin [44,45]. The gut microbiome is a dynamic assembly of microorganisms and the resultant products of their collective genetic and metabolic materials, containing from 2 to 20 million microbial genes by the human microbiome's predominantly in the gut [44]. The gut microbiome plays an array of biological functions ranging from controlling gutimmune system axis, providing several key metabolites and maintaining an optimal digestive system due to the presence of genes, which encode digestive enzymes that are not present in human cells but are associated with the metabolism and fermentation of many food compounds necessary for the host's nutrition [46]. A greater richness and diversity of bacterial species in the human intestine may be an indicator of health $[45,47,48]$.

\section{The Firmicutes/Bacteroidetes Ratio}

\subsection{Short Characteristics of the Firmicutes and the Bacteroidetes}

As the dominant gut microbiota in healthy adult humans [4], intestinal bacteria include members of both the Firmicutes (range of quantitative data-20.5\% up to 80\% [49-53]) and the Bacteroidetes (from $13.85 \%$ up to $75.3 \%$ [20,49,51,52]). Major taxa of the Firmicutes to be included of more than 200 genera [53,54]. Proteobacteria, Fusobacteria, Actinobacteria, Cyanobacteria, and Verrucomicrobia phyla also are present as minor players [54].

Some Bacteroides spp. and Prevotella spp. have a variety of glycans and glycosidases that can utilize polysaccharides [53,55]. Other important functions of Bacteroides spp. include deconjugation of bile acids [56]. The gut microbiota, especially Bacteroides intestinalis, and to a certain extent Bacteroides fragilis and $E$. coli, also has the capacity to deconjugate and dehydrate the primary bile acids and convert them into the secondary bile acids in the human colon [57]. Bacteria belonging to the phylum Bacteroidetes have high functional redundancy, whereas the phylum Firmicutes was comprised of a large number of more functionally diverse core bacteria $[53,54,58]$. Commensal Clostridial clusters XIVa and IV plays an important role in the host and gut homeostasis from the metabolic point of view through the production of short-chain fatty acids, normalizes intestinal permeability, involved the brain-gut axis regulation, in the immune system development, etc. [59]. Many Firmicutes' abilities are related to the host's body weight: obesity-associated gut microbiota is enriched in Clostridium leptum [54], Roseburia intestinalis, Eubacterium ventriosum, Eubacterium hallii [60], Lactobacillus reuteri [42], Blautia hydrogenotorophica, Coprococcus catus, Ruminococcus bromii, Ruminococcus obeum [50]. However, other Firmicutes are abundant in non-obese individuals: Clostridium cellulosi, associated with the degradation of plant material [60,61], Clostridium orbiscindens (currently known as Flavonifractor plautii), capable of utilizing flavonoids [52], Clostridium bolteae, Blautia wexlerae [58], Clostridium difficile, the Staphylococcus genus [40], Oscillospira guillermondii [60], Faecalibacterium (prausnitzii), Lactobacillus plantarum, and paracasei [42]. Also, two Bacteroides species (B. faecichinchillae and B. thetaiotaomicron) [58] and Akkermansia muciniphila, and Methanobrevibacter smithii [42] were significantly more abundant in stool samples from non-obese compared with obese subjects. Such differences in the "behaviour" of bacteria cannot be explained only by their metabolic properties, because of the exact functions of bacteria are still unclear.

\subsection{The Story of "Discovery" of the Firmicutes/Bacteroidetes Ratio}

Increased efficiency of energy harvest, due to alterations in the gut microbiota has been implicated in obesity in mice [31,32,62] and humans [38].Alterations affecting the dominant intestinal phyla the Firmicutes and the Bacteroidetes were first described by Ley et al. (2005) in obese animals [1]. In the analysis of the cecal microbiota (by the 16S rRNA gene sequences) of genetically obese ob/ob mice, lean ob/+ and wild-type +/+ siblings, $\mathrm{ob} / \mathrm{ob}$ animals have a 50\% reduction in the abundance of Bacteroidetes and a proportional increase in Firmicutes compared with lean mice [1]. The authors also pointed out that an increase ofthe Firmicutes / Bacteroidetes ratio may help promote adiposity in $o b / o b$ mice. 
The Firmicutes/Bacteroidetes ratio is also under debate as a possible biomarker of obesity and related dysfunctions [53,62-66]. A low Firmicutes/Bacteroidetes ratio was found to be associated with lean phenotypes, younger age, cardiovascular health, and a balanced immune system and is generally considered beneficial for health [67-69].

\subsection{The Firmicutes/Bacteroidetes Ratio in Obesity: Pro}

Ley et al. (2006) have shown that the microbiota in obese subjects shows an elevated proportion of the Firmicutes and a reduced population of the Bacteroides. Conversely, the relative proportion of the Bacteroidetes decreased in humans on a weight-loss program [30]. 16S rRNA gene sequencing revealed a lower proportion of Bacteroidetes, more Actinobacteria in obese versus lean individuals, but no significant difference in Firmicutes in 31 monozygotic twin pairs and 23 dizygotic twin pairs [33]. Armougom et al. [34] confirmed a reduction in the Bacteroidetes community in 20 obese patients compared with 20 normal-weight individuals $(p<0.01)$. Zuo et al. (2011) reported that obese people had fewer cultivable Bacteroides than their normal-weight counterparts [37]. In the gut in obese adolescents, the total microbiota was more abundant on the phylum Firmicutes (94.6\%) as compared with Bacteroidetes (3.2\%) [39]. In the systematic review (PubMed: 2005-2017) adecrease in the Bacteroidetes phylum and Bacteroides/Prevotella groups was related to high BMI and the Firmicutes phylum was positively correlated with weight gain in children between 0 and 13 years of age [40]. In an adult Ukrainian population, the Firmicutes/Bacteroidetes ratio was significantly associated with BMI (OR = 1.23, 95\% CI 1.09-1.38) and this association continued to be significant after adjusting for confounders such as age, sex, smoking and physical activity $(\mathrm{OR}=1.33,95 \% \mathrm{CI} 1.11-1.60)$ [41]. The recent systematic review confirmed that individuals with obesity have a greater the Firmicutes/Bacteroidetes ratio, more Firmicutes, Fusobacteria, Proteobacteria, Mollicutes, and less Bacteroidetes [42].

\subsection{The Firmicutes/Bacteroidetes Ratio in Obesity: Contra}

However, other human trials not only failed to confirm a high proportion of Firmicutes in obese patients $[63,70-78]$ and, but reported even the opposite: about higher amounts of Bacteroidetes, and decreased amounts of Clostridium cluster XIVa in obese subjects as compared with lean donors [71]. Proportions of the genus Bacteroides were greater in overweight volunteers than lean and obese volunteers and the Firmicutes/Bacteroidetes ratio changed in favour of the Bacteroidetes in overweight and obese subjects [72]. Duncan et al. (2008) found that weight loss did not change the relative proportions of the Bacteroides spp, or the percentage of the Firmicutes present, in the human gut [73]. In another study, no significant differences in the Firmicutes/Bacteroidetes ratios were found between obese and normal-weight adults [74] or obese and normal-weight children [75]. Two meta-analyses have shown that the content of the Firmicutes and the Bacteroidetes and their ratio is not a consistent feature distinguishing lean from obese human microbiota generally [76,77].

Many authors have concluded that there is no simple taxonomic signature of obesity in the microbiota of the human gut and that significant technical and clinical differences exist between published studies [63] and that the phylum level difference of the gut microbiota between obese and lean individuals might not be universally true [78]. Likely explanations for these controversies are discussed below.

\section{Role of the Microbiota in the Pathogenesis of Gallstone Disease}

The pathogenesis of cholesterol GSD is multifactor, it is determined by five primary defects: genetic background and LITH genes, hepatic hypersecretion of biliary cholesterol, rapid precipitation of solid cholesterol crystals in bile, gallbladder dysmotility, and intestinal factors (with increased absorption of cholesterol, slow intestinal motility, and dysbiosis) [10].

In recent years, attention has been focused on the potential impact of the gut microbiota on the pathogenesis of pigment and cholesterol gallstones. It is proved that intestinal dysbiosis makes a significant contribution to the development of not only the GSD it- 
self $[5,6,79-82]$, but also to the development of numerous disorders that are risk factors for GSD, including obesity [31-42], type 2 diabetes [83], hypercholesterolemia [20,52], diet [84], NAFLD [85-88], cardiovascular diseases [68,89], physical inactivity $[29,90,91]$, etc.

Gut microbiota affects the pathogenesis of GSD through several mechanisms. Some bacteria alter the composition of bile directly via $\beta$-glucuronidase, cholyl-glycyl hydrolase, phospholipase A1, or urease activities, or by biofilmformationthereby promoting calcium bilirubinate (pigment) stone generation [92,93]. Till now, it has not been clear whether bacterial pathogens of the biliary tree contribute to the stone formation or alternatively if the presence of gallstones promotes chronic colonization [15]. The activity of the gut microbiota could also be linked to the development of GSD by altering the concentration of serum lipids [94], and biliary lipids in bile and/or increasing the faecal excretion of bile salts [95]. Gut microbiota can modulate bile acid metabolism through the activity of bile salt hydrolases, which deconjugate bile acids, and the activity of $7 \alpha$-dehydroxylase, which converts primary bile acids (cholic acid and chenodeoxycholic acid) to secondary bile acids (deoxycholic acid and lithocholic acid) [94].

Bile acids regulate metabolism via activation of specific nuclear receptors (e.g., farnesoid $X$ receptor, pregnane $X$ receptor, vitamin $D$ receptor, and cell surface $G$ protein-coupled receptors, such as the G protein-coupled bile acid receptor (TGR5 and Gpbar-1)) [96,97]. The effect of the farnesoid $X$ receptor is antilithogenic:farnesoid $X$ receptor activation in the intestine by bile acids induces fibroblast growth factor 15 expression, which suppresses the expression of cholesterol $7 \alpha$-dehydroxylase in the liver [98]. Gallstone patients had significantly higher levels of $7 \alpha$-dehydroxylating bacteria than individuals without gallstones [99]. The increase of $7 \alpha$-dehydroxylation activity of the intestinal microflora promoted the deoxycholic acid excess in the bile acid pool [100], and the increase in the percentage of deoxycholic acid in bile and bile acid hydrophobicity leads to a decrease in the cholesterol microcrystal nucleation time and the formation of cholesterol gallstones [101].

\section{The Firmicutes/BacteroidetesRatio and GSD}

\subsection{Gut Microbiota}

\subsubsection{Gut Microbiota in Mice and Cholelithiasis}

Many reports are underlining the association of the gut microbiota with the pathogenesis of cholesterol cholelithogenesis in mice $[15,102,103]$ and humans $[5,6,80-82,93,100,104-$ 119].

Alteration of indigenous gut microbiota by bacteria transferring has been shown to make germ-free mice more susceptible to the formation of cholesterol gallstones [102]. In a study of mice without and with cholesterol gallstones (induced by a lithogenic diet) using 16S rRNA gene sequencing, it was found that in the faeces of mice, the Firmicutes/Bacteroidetes ratio and the Firmicutes content decreased (from $59.71 \%$ under chow diet to $31.45 \%$ under lithogenic diet, $p<0.01$ ), the richness and alpha diversity of the microbiota also significantly reduced [103]. Cholelithogenic enterohepatic Helicobacter spp. (phylum Proteobacteria) have been identified and their important role in the formation of cholesterol gallstones in mice and perhaps in humans has been shown [15].

\subsubsection{Gut Microbiota in Humans and Gallstones}

In the gallstone group included 30 patients, the diversity of intestinal bacteria and the abundances of certain phylogroups significantly decreased, especially Firmicutes, the Firmicutes/Bacteroidetes ratio was also significantly decreased compared with the control group included 30 healthy individuals [6]. $7 \alpha$-dehydroxylating gut bacteria (the Clostridium genus) were significantly increased, whereas cholesterol-lowering bacteria (the Eubacterium genus) were significantly reduced. Clostridium was positively correlated with secondary bile acids. It can be assumed that an increase in Clostridium and a decrease in Eubacterium contribute to bile saturation with cholesterol in patients with gallstones [100]. In the gallstone group, Ruminococcus gnavus could be used as a biomarker, while in the control group-Prevotella 9 and Faecalibacterium [6]. 
Keren et al. (2015) showed that intestinal microbial diversity, the abundances of the genus Roseburia and the species Bacteroides uniformis were decreased, and those of the family Ruminococcaceae and the genus Oscillospira were increased in patients with gallstones before cholecystectomy compared with the controls [5]. After cholecystectomy in the patients with gallstones, the abundance of the phylum Bacteroidetes, and also the family Bacteroidaceae and the genus Bacteroides showed a significant increase. Gallstone patients had higher overall concentrations of faecal bile acids [5]. Roseburia was significantly positively correlated with faecal cholesterol, but not with bile acids; Oscillospira correlated negatively with primary bile acids and faecal cholesterol concentration and positively-with the secondary bile lithocholic acid in the faeces. Thus, the authors suggest that Oscillospira may predispose individuals to cholesterol gallstones [5]. Cholecystectomy alters bile flow into the intestine and bidirectional interactions between bile acids and intestinal microbiota, thereby increasing bacterial degradation of bile acids into faecal secondary bile acids [104,105]. Deoxycholic acid can inhibit the growth of thececal microbiota in rats; moreover, members of the Bacteroidetes phylum (Bacteroides vulgatus, Bacteroides sartorii) are more sensitive to secondary bile acids exposure than members of the Firmicutes phylum (Clostridium innocuum, Blautia coccoides) [120]. Deoxycholic acid concentrations were negatively correlated with the Bacteroidetes phylum in patients with GSD [5]. Increasing levels of the cholic acid cause a dramatic shift toward the Firmicutes (from $54.1 \%$ before of administration of cholic acid up to $95 \%$ after [120]), particularly Clostridium cluster XIVa and increasing production of the harmful deoxycholic acid [104,121].

Wang $\mathrm{W}$ et al. (2018) identified ageing-associated faecal microbiota in a healthy population, which was lost in cholecystectomy patients [81]. Absent intestinal bacteria, such as Bacteroides, were also negatively related to secondary bile acids in cholecystectomy patients. The abundances of Prevotella, Desulfovibrio, Barnesiella, Paludibacter, and Alistipes all decreased, whereas those of Bifidobacterium, Anaerostipes, and Dorea all increased in the cholecystectomy patients [81].

In the frame of a case-control study, Yoon W et al. (2019) showed that Blautia obeum and Veillonella parvula, which have azoreductase activity, were more abundant in faecal samples in the 27 patients of the cholecystectomy group compared to the control group [82]. The abundance of family Muribaculaceae belonging to the phylum Bacteroidetes was decreased and that of the family Lactobacillaceae was increased in the cholecystectomy group. At the genus level, the abundance of Ruminococcus was greater in the cholecystectomy group [82].The actual number of taxa observed in a faecal sample was significantly lower in the cholecystectomy group. However, the difference in the diversity of the gut microbiota between the cholecystectomy and control groups was subtle [82].

Two years after cholecystectomy, eight patients with the symptomatic post-cholecystectomy syndrome, eight patients with the asymptomatic post-cholecystectomy syndrome, and eight healthy individuals were examined [106]. It was shown that Firmicutes and Bacteroidetes had similar abundance and contents among the three groups. The gut microbiome of the symptomatic post-cholecystectomy syndrome patients was dominated by Proteobacteria in faeces and contained little Firmicutes and Bacteroidetes [106].

Wu et al. (2013) studied the composition of bacterial communities of the gut, bile, and gallstones from 29 cholesterol gallstone patients and the gut of 38 healthy controls [107] by $16 \mathrm{~S}$ rRNA gene sequencing method. They found a significant increment of the gut bacterial phylum Proteobacteria anddecrement of gut bacterial genera Faecalibacterium, Lachnospira, and Roseburia. When compared with gut, a significantly decreased level of the bacterial phylum Bacteroidetes in the biliary tract was found. The Firmicutes/Bacteroidetes ratio in faeces in patients with GSD did not differ in comparison with the control group [107].

Ren X et al. (2020) examined stool samples from 104 subjects (equally post-cholecystectomy patients and healthy controls) which were collected for $16 \mathrm{~S}$ rRNA gene sequencing to analyze the bacterial profile [80]. It was shown noteworthy compositional and abundant alterations of bacterial microbiota in post-cholecystectomy patients, characterized as Bacteroides ovatus, Prevotella copri, and Fusobacterium varium remarkably increased; 
Faecalibacterium prausnitzii, Roseburia faecis, and Bifidobacterium adolescentis significantly decreased. Machine learning-based analysis, that integrates gut microbiota and other anthropometric parameters, showed a pivotal role of Megamonas funiformis in discriminating post-cholecystectomy patients from healthy controls. Additionally, the duration after cholecystectomy notably affected bacterial composition in post-cholecystectomy patients [80].

Eventually, if we summarize the results of most studies of the microbiota in patients with GSD different authors found both a significant increment of gut bacterial phyla Firmicutes (Lactobacillaceae family, genera Clostridium, Ruminococcus, Veillonella, Blautia, Dorea, Anaerostipes, and Oscillospira), Actinobacteria (Bifidobacterium genus), Proteobacteria, Bacteroidetes (genera Bacteroides, Prevotella, and Fusobacterium) (Figure 1) and significant decrement of gut bacterial phyla Bacteroidetes (Muribaculaceae family, and genera Bacteroides, Prevotella, Alistipes, Paludibacter, Barnesiella), Firmicutes (genera Faecalibacterium, Eubacterium, Lachnospira, and Roseburia), Actinobacteria (Bifidobacterium genus), and Proteobacteria (Desulfovibrio genus) (Figure 2). In other words, in patients with GSD, an increase and decrease in almost all major intestinal bacterial phyla were detected. In one study the Firmicutes/Bacteroidetes ratio in faeces in patients with GSD was significantly decreased in comparison with the controls [6], in two studies-did not differ [106,107]. In addition to Firmicutes and Bacteroidetes as the main phyla, Proteobacteria and other phyla may contribute to the gut dysbiosis in patients with GSD.

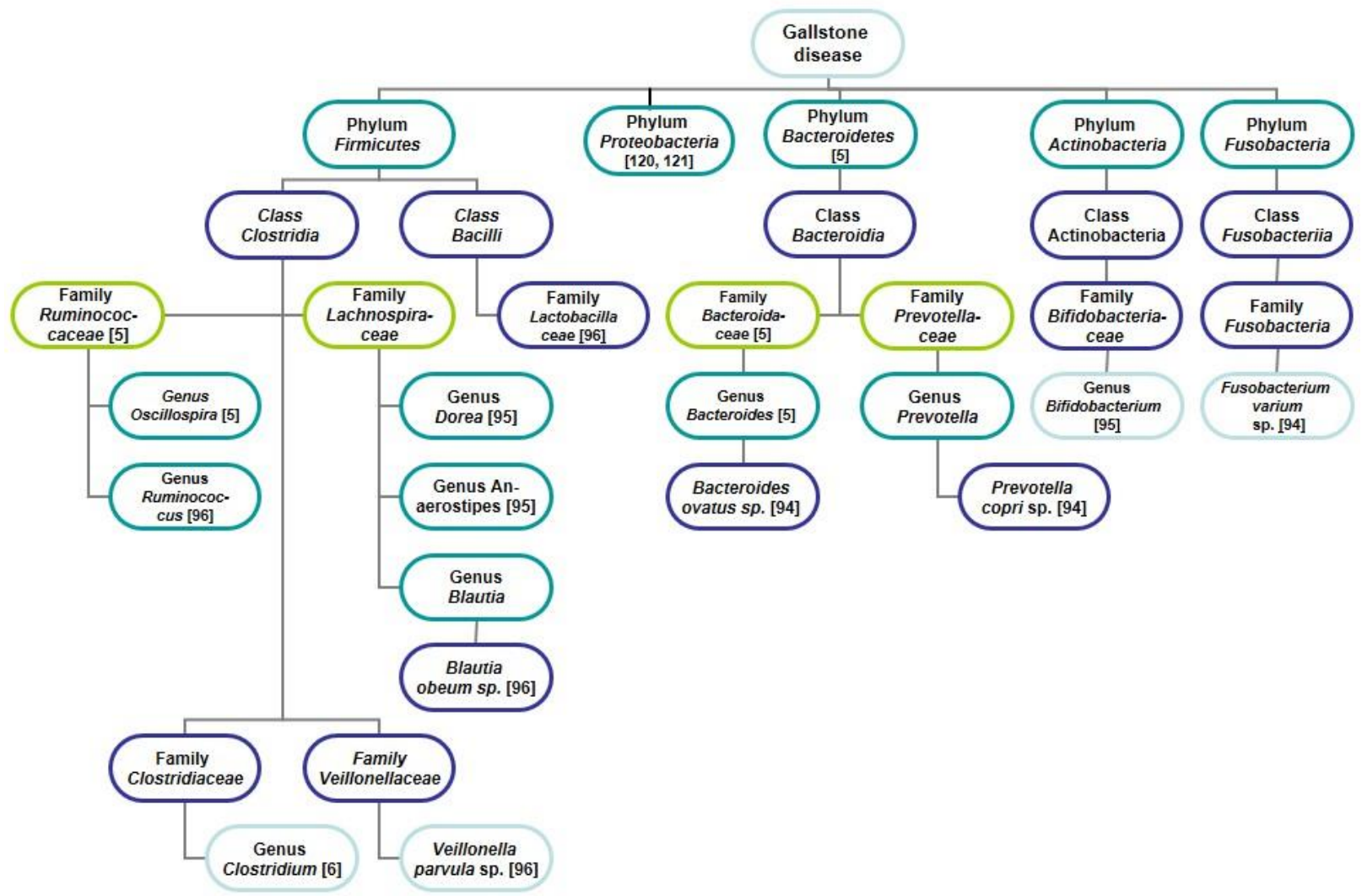

Figure 1. Characteristics of the gut microbiome of patients with GSD. A significant increase of the phyla Firmicutes, Actinobacteria, Proteobacteria, and Bacteroidetes is reflected. The number in square brackets indicates a reference in the list of references. 


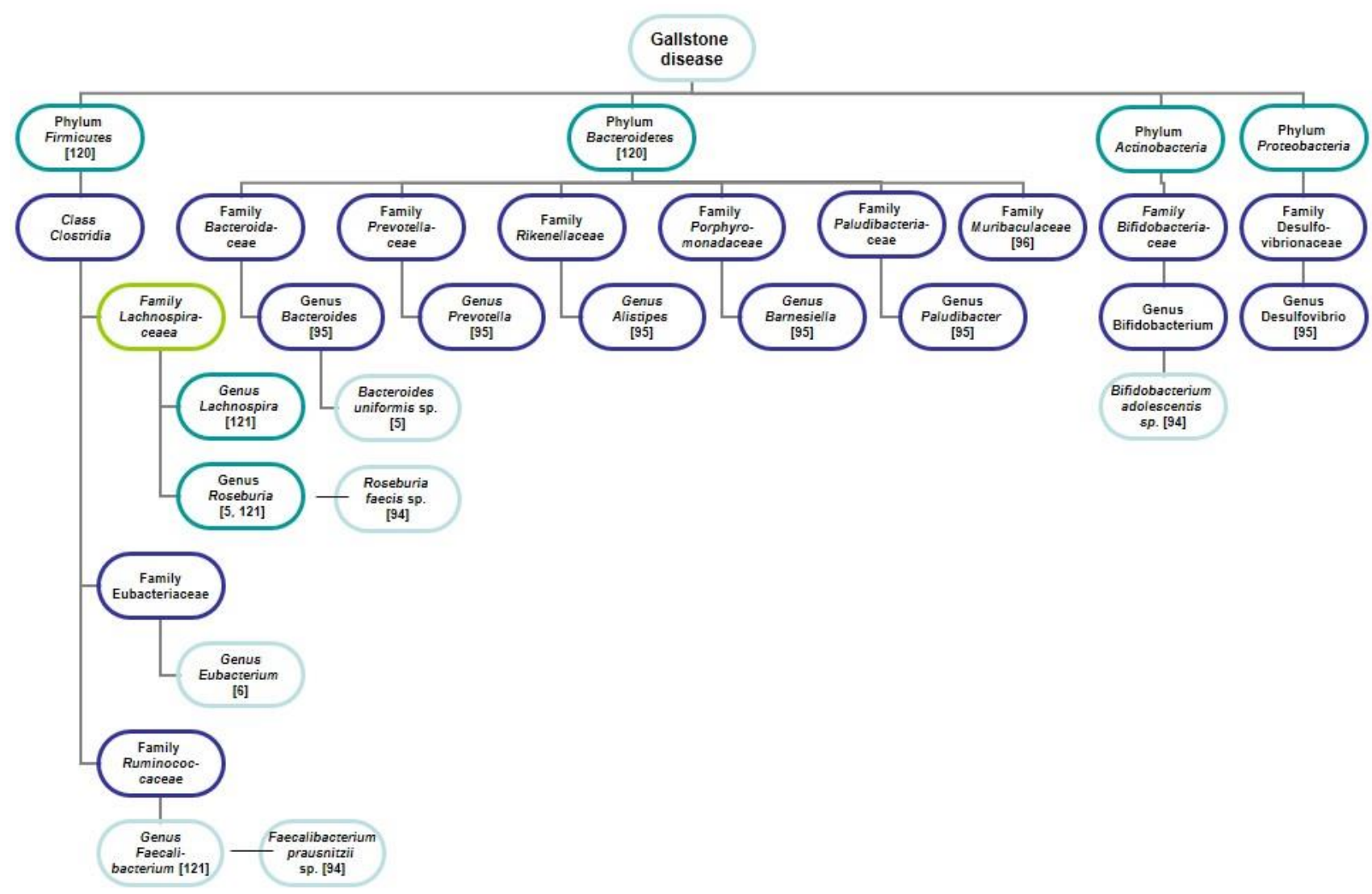

Figure 2. Characteristics of the gut microbiome of patients with GSD. A significant decrease of the phyla Firmicutes, Actinobacteria, Proteobacteria, and Bacteroidetes is reflected. The number in square brackets indicates a reference in the list of references.

Using metagenomic DNA sequencing, researchers have been able to categorize individuals as either high gene count (HGC) or low gene count (LGC) [44]. HGC individuals are generally considered to have a greater repertoire of microbial metabolic functions, a functionally more robust gut microbiome, and greater overall health, including a lower prevalence of obesity and metabolic disorders [48]. Examples of bacterial taxa that have been associated with human health and proper gastrointestinal function include Bacteroides, Bifidobacterium, Clostridium clusters XIVa and IVa (butyrate producers), Eubacterium, Faecalibacterium, Lactobacillus, and Roseburia. Bacterial species that might protect against weight gain and are enriched in HGC individuals include Anaerotruncus colihominis, Butyrovibrio crossotus, Akkermansia spp., and Faecalibacterium spp. [48]. The studies of the gut microbiota in patients with GSD included in our review demonstrated a reduction of bacterial taxa that have been associated with human health, i.e., genera Bacteroides, Faecalibacterium, Roseburia, Eubacterium, an increase in Lactobacillaceae family, and oppositely directed changes in Bifidobacterium.

\subsubsection{Bile Microbiota in Humans and Gallstones}

The presence of bacterial amplicons belonging to Firmicutes, Bacteroidetes, and Actinobacteria, and Proteobacteria phyla in the human intact gallbladder bile was proved by $16 \mathrm{~S}$ rRNA gene sequencing $[108,109]$. Associations between alpha- and beta-diversity, a taxonomic profile of bile microbiota (Bacteroidetes, Proteobacteria, Actinobacteria, and Firmicutes phyla, analyzed with $16 \mathrm{~S}$ rRNA gene sequencing), and taurocholic and taurochenodeoxycholic bile acid levels were evidenced in 37 Russian patients with GSD [110].

At the phylum level, Bacteroidetes was statistically more abundant in the bile of patients with GSD (24.00\%) compared to the control (13.49\%) [109]. Members of the families Bacteroidaceae, Prevotellaceae, Porphyromonadaceae, and Veillonellaceae were more frequently 
detected in patients with GSD. The genus Dialister and enterobacteria Escherichia-Shigella also showed a significantly higher representation in the bile in the patients with GSD [109]. The Shannon diversity index was statistically higher in the bile of the control group than that obtained in the patients with GSD [102].However, it was not taken into account that bile samples from the gallbladder of individuals from a control group were obtained from liver donors, and they were not only treated with antibiotics but also not fully examined to exclude hepatobiliary or other important pathology [109].

The Proteobacteria, Firmicutes, Bacteroidetes, and Actinobacteria phyla dominated the biliary microbiota in the persons, all of whom were diagnosed with GSD, at that biliary tract microbiota of participants with GSD showed substantial person-to-person variation [79]. Metagenomic sequencing of bile from gallstone patients showed that oral cavity/respiratory tract inhabitants were more prevalent than intestinal inhabitants [108]. At the same time, bile samples from gallstone patients had reduced microbial diversity compared to healthy faecal samples [108]. Among patients with the new onset of common bile duct stones, five dominant phyla were identified: Proteobacteria $(60 \%)$, Firmicutes $(27 \%)$, Bacteroidetes (4\%), Actinobacteria (3\%), and Unclassified_Bacteria (3\%) in biliary microbiota [111]. At the genus level, the five genera with the highest relative abundances in patients with the new onset of common bile duct stones were Escherichia/Shigella, Halomonas, Klebsiella, Streptococcus, and Enterococcus [111].

In patients with cholangiolithiasis associated with sphincter of Oddi laxity, Proteobacteria and Firmicutes were the most widespread phylotypes, especially Enterobacteriaceae, in the bile, which was collected intraoperatively [112]. In the bile of the cholecystectomized gallstone patients Escherichia coli, Salmonella sp., and Enterococcusgallinarum were detected by using next-generation sequencing technology [113]. Enterobacteriaceae are frequently isolated from bile aspirates or gallbladder bile from GSD patients using cultural $[114,115]$ and culture-independent techniques [116,117]. The biliary microbiota (investigated by using $16 \mathrm{~S}$ rRNA amplicon sequencing) had a reduced diversity comparatively with the duodenal microbiota in gallstone patients [117]. Although the majority of identified bacteria were greatly diminished in bile samples, three Enterobacteriaceae genera (Escherichia, Klebsiella, and an Unclassified genus) and Pyramidobacter were abundant in bile [117].

In terms of bile microbial distribution, analyzed by the $16 \mathrm{~S}$ rRNA encoding gene (V3-V4), patients with recurrent common bile duct stone had significantly higher Proteobacteria, while Bacteroidetes and Actinobacteria are significantly lower compared with the control group at the phylum level [117]. At the family level, Enterobacteriaceae was significantly abundant in the bile samples of the recurrence stone group compared with the control group. At the genus level, the recurrence stone group had significantly more Escherichia. The diversity of bile microbiome in patients with recurrent common bile duct stone is lower than that in the control non-cholelithiasis group [117].

During a cholecystectomy, mucosal DNA extraction and metagenomic sequencing were performed to evaluate changes in the microbiota between chronic calculous cholecystitis and gallbladder cancer patients [118]. At the phylum level, Firmicutes, Bacteroidetes, Actinobacteria, and Proteobacteria were found to be stable in both groups. The diversity of the biliary microbiota was significantly lower in the calculous cholecystitis group, compared with the gallbladder cancer group [118].

In four patients who underwent cholecystectomy for acute calculous cholecystitis metagenome analysis of bile, faeces, and saliva was performed [119]. In all the examined patients with acute calculous cholecystitis, Escherichia coli (Enterobacteriaceae family) was found in large quantities in the bile, in two of them-also in the faeces, in the third patient, Bifidobacterium prevailed in the faeces. This is not enough to conclude the relationship between the intestinal microbiota and acute calculous cholecystitis, since if bile samples were taken during surgery, then saliva and faeces were collected by patients during hospitalization (it is not clear before or after the cholecystectomy) [119]. 
During endoscopic retrograde cholangiopancreatography, a total of 44 bile samples of patients with GSD were collected. Bacterial infection in bile samples was detected in $54.5 \%$ of patients with GSD. Escherichia coli showed a significant association with gallstones [122].

Thus, bile samples from patients with GSD had reduced microbial diversity in some studies and increased microbial diversity in others compared to healthy faecal samples. Nevertheless, most authors recognize that patients with GSD have reduced bacterial diversity of intestinal and bile microbiota. The phyla Proteobacteria (especially family Enterobacteriaceae) and Firmicutes (Enterococcus genus) were more often detected in the bile of patients with GSD, and the phyla Bacteroidetes and Synergistes (Pyramidobacter genus) were less frequently detected.

Some reports described live bacteria and bacterial DNA as long-term constituents in different fat depots in obesity and diabetes mellitus type $2[123,124]$. In humans with the metabolic syndrome, altered microbiome composition together with a defective intestinal barrier has been suggested to facilitate translocation of microbes, thereby contributing to low-grade inflammation. A recent study demonstrated a bacterial signature in mesenteric adipose tissues without the obvious presence of blood: members of the Enterobacteriaceae family compartmentalize in the extra-intestinal tissues of people with diabetes mellitus type 2 independently of obesity [123]. The authors suggest that members of the Enterobacteriaceae family are key players in diet-induced dysmetabolism in the host. Unfortunately, the intriguing topic of possible translocation of living bacteria (perhaps even members of the Enterobacteriaceae family) from the gut to other body sites in patients with GSD remains undiscovered.

So, when analyzing available studies of intestinal and bile microbiota in animals and patients with GSD $[5,6,15,79-82,92,93,100,102-119]$ there were no unidirectional changes in the Firmicutes/Bacteroidetes ratio. This situation with opposite results is typical not only for GSD. For comparison, we will briefly present the results of several studies reporting differences in phylum levels in patients with non-alcoholic fatty liver disease (usually associated with obesity): the phylum Bacteroidetes-increased [86], decreased [88,125], did not differ [87,126], the phylum Firmicutes-decreased [86,87], increased [126], and the Firmicutes / Bacteroidetes ratio decreased [88].

This variation in the relative abundance of the phylum of the gut corresponds to the analysis of seven studies in Finucane et al. (2014): Bacteroidetes-from 0\% to 90\%, Firmicutesfrom 0 to $100 \%$ [63]. This also applies to GSD. For example, the highest abundance of Firmicutes phylum in the human gastrointestinal tract in one GSD patient was $93.30 \%$ and the lowest was $1.17 \%$ in another. A similar result was also seen in bile with a high of $55.10 \%$ and low of $0.08 \%$ [107]. In another study, the range of relative abundance of Firmicutes phylum was 0-92\% in the bile of patients with GSD [79].

\section{Some Reasons for the Lack of Unity in the Assessment of the Firmicutes/Bacteroidetes Ratio}

Gut microbiota is changing with human development and is influenced by many confounding variables which could prevent the existence of a unique taxonomic signature as a standard feature for obesity and associated comorbidities such as GSD [64,83,89].

1. Gender, age, differences in host genetics [4]. There are differences in the gut microbiota between males and females, such as higher levels of Bacteroides-Prevotella group in males [127] and a higher proportion of Firmicutes in females [128]. However, Bezek et al. (2020) found the highest abundance of Bacteroidetes phylum in females [51]. The Firmicutes/Bacteroidetes ratio evolves during different life stages. For infants (up to 10 months), adults (25-45 years), and elderly individuals (70-90 years), these ratios were $0.4,10.9$, and 0.6 , respectively [44].

2. Vaginal delivery or C-section, methods of milk feeding [129].

3. Changes in the gut microbiota under the influence of a variety of diets have been widely studied $[30-32,35,36,38,47,52,62,72,73,84,91,129-131]$. It was noted that the amount of stool energy in a proportion of ingested calories was positively correlated 
with the abundance of the phylum Bacteroidetes and negatively-with the abundance of the phylum Firmicutes in the faeces [38]. As a rule, the "western diet" increases biliary secretion of bile acids and reshapes the gut microbiota in obesity by increasing the Firmicutes and decreasing the Bacteroidetes [35,62]. Several population-based studies have shown that populations given increased amounts of polyunsaturated fats have a significant risk of developing gallstones [9,12,132-134]. The MICOL study, however, showed no such association [135]. Gutiérrez-Díaz et al. (2018) support a link between diet, biliary microbiota, and GSD [84]. Comparing to health control in patients with GSD, dairy product intake was negatively associated with the proportions of Bacteroidaceae and Bacteroides, and several types of fibre, phenolics, and fatty acids were linkedto the abundance of Bacteroidaceae, Chitinophagaceae, Propionibacteraceae, Bacteroides, and Escherichia-Shigella [84]. However, the timing of these changes is surprising. In response to dietary perturbations, the gut microbiota took from 24 h [130] to 3.5 days [36] to change detectably and reaches a new steady state. Repeated dietary shifts demonstrated that most changes to the gut microbiota are reversible [36]. Also, Carmody et al. (2015) suggest, that the effects of dietary intake overshadow any pre-existing differences between strains due to host genotype [36]. Add to this the inter-individual variability in the processing of dietary compounds by the human gastrointestinal tract [136] and the hope of finding patterns in the relationship "microbiota-host-diet" becomes quite vague.

4. The presence of pathological conditions (diabetes mellitus [83], cardiovascular disease [89], inflammatory bowel disease [64], etc.). For example, the sphincter of Oddi laxity is associated with cholangiolithiasis, probably due to enhanced reflux of intestinal contents that change the microenvironment [112]. Compared with patientswith cholangiolithiasis with normal sphincter of Oddi, patients with sphincter of Oddi laxity possessed more varied microbiota [112].

5. Treatment (antibiotics [137], metformin [138], etc.). Metformin shifts gut microbiota composition through the enrichment of Akkermansia muciniphila as well as several SCFA-producing microbiotas (Butyrivibrio, Bifidobacterium bifidum, etc.) [138].

6. The influence of exercise training on the gut microbiome has also been examined [29, 91,131] and it has been shown that exercise alone increased the Firmicutes/Bacteroidetes ratio, irrespective of diet [91].

7. Human microbiota differs according to the geographical location of the studies [113, 139-141]. It was found a positive correlation between Firmicutes and latitude and a negative correlation between Bacteroidetes and latitude [139]. In the frame of study of human gut microbiota community structures in urban and rural populations in Russia, two clusters were obtained: the first was driven by the genus Prevotella, and the second exhibited a high representation of Bifidobacterium and various genera of the phylum Firmicutes. The urban and rural metagenomes were distributed equally between the clusters: $53 \%$ of the first and $52 \%$ of the second cluster were urban [141].

8. Lifestyle. Sleep deprivation correlates with changes in the gut microbiome, with an increase of the Firmicutes/Bacteroidetes ratio, higher abundances of the families Coriobacteriaceae and Erysipelotrichaceae, and lower abundance of Tenericutes [51,142]. Stress, occupation, temporal dynamics and stability of the microbiome: diurnal oscillations in the relative abundance of almost $10 \%$ of all bacterial taxawere detected [143].

9. The extreme variability of the Firmicutes/Bacteroidetes ratio can be attributed to the different experimental designs (insufficient sample size [144]), microbiota fingerprinting, and genome analyses (choice of the primers the 16S rRNA target region, DNA extraction technique [145], and sequencing platform) [50,146]. Besides, members of the Bacteroidetes and Actinobacteria were significantly more stable components of the microbiota than the population average, while the Firmicutes and Proteobacteria were significantly less stable [147]. The plasticity vs. stability dichotomy of the human microbiome was confirmed in a study by David et al. (2014): when analyzing microbiota samples over several months, only $5 \%$ of the gut species were defined as belonging to 
a stable temporal core microbiome. Yet, each person still maintained a personalized microbiome [140].

10. There are also hard-to-determine factors, such as the Earth's geomagnetic field, weather, etc.

\section{Conclusions}

Meta-analysis has shown that the microbial changes associated with obesity may be minor shifts in the community that escape detection with significance tests [77]. It may be the case that the microbiome's effect on obesity is not mediated through its taxonomic composition but rather its function, since closely related taxa can have widely varying functions and distantly related taxa can have similar functions [63]. It is proved that variable combinations of species from different phyla could 'presumptively' fulfil overlapping and/or complementary functional roles required by the host, a scenario where minor bacterial taxa seem to be significant active contributors [39]. For example, the cocolonization of germ-free mice with $B$. Thetaiotaomicron and $E$. rectale constitutes a mutualism, in which both members show a clear benefit [148] and the efficiency of fermentation of dietary polysaccharides to short-chain fatty acids by $B$. thetaiotaomicron increases in the presence of M. Smithii [149].

Based on the analysis of the great number of contradictory results reported in the literature, it is currently difficult to associate specific microbial signatures or the Firmicutes/Bacteroidetes ratio with determining health status and more specifically to consider it as a hallmark of GSD and/or obesity. However, most authors believe that both obesity $[33,34,40,48,64,130]$ and GSD $[5,6,81,103,109,111,117-120]$ are associated with reduced microbial diversity.Therefore, it is important to look at the overall composition of the gut microbial population structure as an indicator of obesity and obesity-associated pathologies, such as GSD, rather than simply the Firmicutes/Bacteroidetes ratio [150]. However, in my opinion, it is possible to modify this ratio, e.g., to introduce a coefficient that characterizes BMI, to calculate the ratio not of the Firmicutes phylum, but only of the Clostridia class, and so on.

Further studies should focus on the possibility of modulating the intestinal microbiota to find out whether variations in the microbiota may be a target for lowering the risks and prevalence rates of GSD. Future studies to identify specific bacterial species or populations associated with the obesity or GSD phenotype will help optimize disease therapies through microbiome-informed patient stratification, through personalized treatment decisions. A better understanding of bacterial communities in both the gut and biliary tract of gallstone patients is crucial in developing strategies to promote personalized microbiome-based GSD prediction and treatment responsiveness.

Funding: This study was performed according to the framework of the budget theme of the State assignment no. AAAA-A17-117112850280-2 and with the financial support of the Biocodex MICROBIOTA Foundation, France.

Institutional Review Board Statement: Not applicable.

Informed Consent Statement: Not applicable.

Ethical Statement:: The author is accountable for all aspects of the work in ensuring that questions related to the accuracy or integrity of any part of the work are appropriately investigated and resolved.

Data Availability Statement: Not applicable.

Conflicts of Interest: The author declares no conflict of interest. The funders had no role in the design of the study; in the collection, analyses, or interpretation of data; in the writing of the manuscript, or in the decision to publish the results.

\section{References}

1. Ley, R.E.; Bäckhed, F.; Turnbaugh, P.; Lozupone, C.A.; Knight, R.D.; Gordon, J.I. Obesity alters gut microbial ecology. Proc. Natl. Acad. Sci. USA 2005, 102, 11070-11075. [CrossRef] [PubMed] 
2. Mathur, R.; Barlow, G.M. Obesity and the microbiome. Expert Rev. Gastroenterol. Hepatol. 2015, 9, 1087-1099. [CrossRef]

3. WHO Overweight and Obesity. Available online: http://www.who.int/gho/ncd/risk_factors/overweight/en/ (accessed on 1 June 2019).

4. Woting, A.; Blaut, M. The Intestinal Microbiota in Metabolic Disease. Nutrients 2016, 8, 202. [CrossRef] [PubMed]

5. Keren, N.; Konikoff, F.M.; Paitan, Y.; Gabay, G.; Reshef, L.; Naftali, T.; Gophna, U. Interactions between the intestinal microbiota and bile acids in gallstones patients. Environ. Microbiol. Rep. 2015, 7, 874-880. [CrossRef] [PubMed]

6. Wang, Q.; Hao, C.; Yao, W.; Zhu, D.; Lu, H.; Li, L.; Ma, B.; Sun, B.; Xue, D.; Zhang, W. Intestinal flora imbalance affects bile acid metabolism and is associated with gallstone formation. BMC Gastroenterol. 2020, 20, 1-13. [CrossRef]

7. Salinas, G.; Velásquez, C.; Saavedra, L.; Ramírez, E.; Angulo, H.; Tamayo, J.C.; Orellana, A.; Huivin, Z.; Valdivia, C.; Rodríguez, W. Prevalence and Risk Factors for Gallstone Disease. Surg. Laparosc. Endosc. Percutaneous Tech. 2004, 14, 250-253. [CrossRef]

8. Chen, C.-H.; Huang, M.-H.; Yang, J.-C.; Nien, C.-K.; Etheredge, G.D.; Yang, C.-C.; Yeh, Y.-H.; Wu, H.-S.; Yueh, S.-K.; Chou, D.-A. Prevalence and risk factors of gallstone disease in an adult population of Taiwan: An epidemiological survey. J. Gastroenterol. Hepatol. 2006, 21, 1737-1743. [CrossRef]

9. Misciagna, G.; Centonze, S.; Leoci, C.; Guerra, V.; Cisternino, A.M.; Ceo, R.; Trevisan, M. Diet, physical activity, and gallstones-A population-based, case-control study in southern Italy. Am. J. Clin. Nutr. 1999, 69, 120-126. [CrossRef]

10. Di Ciaula, A.; Wang, D.Q.-H.; Portincasa, P. An update on the pathogenesis of cholesterol gallstone disease. Curr. Opin. Gastroenterol. 2018, 34, 71-80. [CrossRef]

11. Liu, T.; Wang, W.; Ji, Y.; Wang, Y.; Liu, X.; Cao, L.; Liu, S. Association between different combination of measures for obesity and new-onset gallstone disease. PLoS ONE 2018, 13, e0196457. [CrossRef]

12. Kiani, Q.; Farooqui, F.; Khan, M.S.; Khan, A.Z.; Tariq, M.N.; Akhtar, A. Association of Body Mass Index and Diet with Symptomatic Gall Stone Disease: A Case-Control Study. Cureus 2020, 12, e7188. [CrossRef] [PubMed]

13. Stahlberg, D.; Rudling, M.; Angelin, B.; Björkhem, I.; Forsell, P.; Nilsell, K.; Einarsson, K. Hepatic cholesterol metabolism in human obesity. Hepatology 1997, 25, 1447-1450. [CrossRef] [PubMed]

14. Wen, H.; Gris, D.; Lei, Y.; Jha, S.; Zhang, L.; Huang, M.T.-H.; Brickey, W.J.; Ting, J. Fatty acid-induced NLRP3-ASC inflammasome activation interferes with insulin signaling. Nat. Immunol. 2011, 12, 408-415. [CrossRef] [PubMed]

15. Maurer, K.J.; Carey, M.C.; Fox, J.G. Roles of Infection, Inflammation, and the Immune System in Cholesterol Gallstone Formation. Gastroenterology 2009, 136, 425-440. [CrossRef]

16. Biddinger, S.B.; Haas, J.T.; Yu, B.B.; Bezy, O.; Jing, E.; Zhang, W.; Unterman, T.G.; Carey, M.C.; Kahn, C.R. Hepatic insulin resistance directly promotes formation of cholesterol gallstones. Nat. Med. 2008, 14, 778-782. [CrossRef]

17. Paramsothy, P.; Knopp, R.H.; Kahn, S.E.; Retzlaff, B.M.; Fish, B.; Ma, L.; Ostlund, R.E., Jr. Plasma sterol evidence for decreased absorption and increased synthesis of cholesterol in insulin resistance and obesity. Am. J. Clin. Nutr. 2011, 94, 1182-1188. [CrossRef]

18. Nakeeb, A.; Comuzzie, A.G.; Al-Azzawi, H.; Sonnenberg, G.E.; Kissebah, A.H.; Pitt, H.A. Insulin Resistance Causes Human Gallbladder Dysmotility. J. Gastrointest. Surg. 2006, 10, 940-949. [CrossRef]

19. Dhamnetiya, D.; Goel, M.K.; Dhiman, B.; Pathania, O.P. Gallstone disease and its correlates among patients attending teaching hospital of North India. J. Fam. Med. Prim. Care 2019, 8, 189-193. [CrossRef]

20. Wang, S.-Z.; Yu, Y.; Adeli, K. Role of Gut Microbiota in Neuroendocrine Regulation of Carbohydrate and Lipid Metabolism via the Microbiota-Gut-Brain-Liver Axis. Microorganisms 2020, 8, 527. [CrossRef]

21. Ceranowicz, P.; Warzecha, Z.; Dembinski, A. Peptidyl hormones of endocrine cells origin in the gut-Their discovery and physiological relevance. J. Physiol. Pharmacol. 2015, 66, 11-27.

22. Abizaid, A. Stress and obesity: The ghrelin connection. J. Neuroendocrinol. 2019, 31, e12693. [CrossRef] [PubMed]

23. Cui, H.; López, M.; Rahmouni, H.C.K. The cellular and molecular bases of leptin and ghrelin resistance in obesity. Nat. Rev. Endocrinol. 2017, 13, 338-351. [CrossRef] [PubMed]

24. Churm, R.; Davies, J.; Stephens, J.W.; Prior, S.L. Ghrelin function in human obesity and type 2 diabetes: A concise review. Obes. Rev. 2017, 18, 140-148. [CrossRef] [PubMed]

25. Bugajska, J.; Gotfryd-Bugajska, K.; Szura, M.; Berska, J.; Pasternak, A.; Sztefko, K. Characteristics of amino acid profile and incretin hormones in patients with gallstone disease-A pilot study. Pol. Arch. Intern. Med. 2019, 129, 883-888. [CrossRef] [PubMed]

26. Mendez-Sanchez, N.; Ponciano-Rodriguez, G.; Bermejo-Martinez, L.; Villa, A.R.; Chavez-Tapia, N.C.; Zamora-Valdes, D.; Pichardo-Bahena, R.; Barredo-Prieto, B.; Uribe-Ramos, M.H.; Ramos, M.H.; et al. Low serum levels of ghrelin are associated with gallstone disease. World J. Gastroenterol. 2006, 12, 3096-3100. [CrossRef]

27. Bungau, S.; Behl, T.; Tit, D.M.; Banica, F.; Bratu, O.G.; Diaconu, C.C.; Nistor-Cseppento, C.D.; Bustea, C.; Aron, R.A.C.; Vesa, C.M. Interactions between leptin and insulin resistance in patients with prediabetes, with and without NAFLD. Exp. Ther. Med. 2020, 20, 1. [CrossRef]

28. Lei, Z.-M.; Ye, M.-X.; Fu, W.-G.; Chen, Y.; Fang, C.; Li, J. Levels of serum leptin, cholecystokinin, plasma lipid and lipoprotein differ between patients with gallstone or/and those with hepatolithiasis. Hepatobiliary Pancreat. Dis. Int. 2008, 7, 65-69.

29. Queipo-Ortuño, M.; Seoane, L.M.; Murri, M.; Pardo, M.; Gomez-Zumaquero, J.M.; Cardona, F.; Casanueva, F.; Tinahones, F.J. Gut Microbiota Composition in Male Rat Models under Different Nutritional Status and Physical Activity and Its Association with Serum Leptin and Ghrelin Levels. PLoS ONE 2013, 8, e65465. [CrossRef] 
30. Ley, R.E.; Turnbaugh, P.J.; Klein, S.; Gordon, J.I. Human gut microbes associated with obesity. Nature 2006, $444,1022-1023$. [CrossRef]

31. Bäckhed, F.; Ding, H.; Wang, T.; Hooper, L.V.; Koh, G.Y.; Nagy, A.; Semenkovich, C.F.; Gordon, J.I. The gut microbiota as an environmental factor that regulates fat storage. Proc. Natl. Acad. Sci. USA 2004, 101, 15718-15723. [CrossRef]

32. Turnbaugh, P.J.; Ley, R.E.; Mahowald, M.A.; Magrini, V.; Mardis, E.R.; Gordon, J.I. An obesity-associated gut microbiome with increased capacity for energy harvest. Nature 2006, 444, 1027-1031. [CrossRef] [PubMed]

33. Turnbaugh, P.J.; Hamady, M.; Yatsunenko, T.; Cantarel, B.L.; Duncan, A.; Ley, R.E.; Sogin, M.L.; Jones, W.J.; Roe, B.A.; Affourtit, J.P.; et al. A core gut microbiome in obese and lean twins. Nature 2008, 457, 480-484. [CrossRef] [PubMed]

34. Armougom, F.; Henry, M.; Vialettes, B.; Raccah, D.; Raoult, D. Monitoring Bacterial Community of Human Gut Microbiota Reveals an Increase in Lactobacillus in Obese Patients and Methanogens in Anorexic Patients. PLoS ONE 2009, 4, e7125. [CrossRef] [PubMed]

35. Murphy, E.F.; Cotter, P.D.; Healy, S.; Marques, T.M.; O’Sullivan, O.; Fouhy, F.; Clarke, S.F.; O'Toole, P.W.; Quigley, E.M.; Stanton, C.; et al. Composition and energy harvesting capacity of the gut microbiota: Relationship to diet, obesity and time in mouse models. Gut 2010, 59, 1635-1642. [CrossRef] [PubMed]

36. Carmody, R.N.; Gerber, G.K.; Luevano, J.M.; Gatti, D.M.; Somes, L.; Svenson, K.L.; Turnbaugh, P. Diet Dominates Host Genotype in Shaping the Murine Gut Microbiota. Cell Host Microbe 2015, 17, 72-84. [CrossRef]

37. Zuo, H.-J. Gut bacteria alteration in obese people and its relationship with gene polymorphism. World J. Gastroenterol. 2011, 17, 1076-1081. [CrossRef]

38. Jumpertz, R.; Le, D.S.; Turnbaugh, P.J.; Trinidad, C.; Bogardus, C.; Gordon, J.I.; Krakoff, J. Energy-balance studies reveal associations between gut microbes, caloric load, and nutrient absorption in humans. Am. J. Clin. Nutr. 2011, 94, 58-65. [CrossRef]

39. Ferrer, M.; Ruiz, A.; Lanza, F.; Haange, S.-B.; Oberbach, A.; Till, H.; Bargiela, R.; Campoy, C.; Segura, M.T.; Richter, M.; et al. Microbiota from the distal guts of lean and obese adolescents exhibit partial functional redundancy besides clear differences in community structure. Environ. Microbiol. 2013, 15, 211-226. [CrossRef]

40. Indiani, C.M.D.S.P.; Rizzardi, K.F.; Castelo, P.M.; Ferraz, L.F.C.; Darrieux, M.; Parisotto, T.M. Childhood Obesity and Firmicutes/Bacteroidetes Ratio in the Gut Microbiota: A Systematic Review. Child Obes. 2018, 14, 501-509. [CrossRef]

41. Koliada, A.; Syzenko, G.; Moseiko, V.; Budovska, L.; Puchkov, K.; Perederiy, V.; Gavalko, Y.; Dorofeyev, A.; Romanenko, M.; Tkach, S.; et al. Association between body mass index and Firmicutes/Bacteroidetes ratio in an adult Ukrainian population. BMC Microbiol. 2017, 17, 120. [CrossRef]

42. Crovesy, L.; Masterson, D.; Rosado, E.L. Profile of the gut microbiota of adults with obesity: A systematic review. Eur. J. Clin. Nutr. 2020, 74, 1251-1262. [CrossRef] [PubMed]

43. Vandana, U.K. Linking gut microbiota with human diseases. Bioinformation 2020, 16, 196-208. [CrossRef] [PubMed]

44. Qin, J.; Li, R.; Raes, J.; Arumugam, M.; Burgdorf, K.S.; Manichanh, C.; Nielsen, T.; Pons, N.; Levenez, F.; Yamada, T.; et al. A human gut microbial gene catalogue established by metagenomic sequencing. Nature 2010, 464, 59-65. [CrossRef] [PubMed]

45. Gilbert, J.A.; Blaser, M.J.; Caporaso, J.G.; Jansson, J.K.; Lynch, S.V.; Knight, R. Current understanding of the human microbiome. Nat. Med. 2018, 24, 392-400. [CrossRef]

46. Cani, P.D. Human gut microbiome: Hopes, threats and promises. Gut 2018, 67, 1716-1725. [CrossRef] [PubMed]

47. Claesson, M.J.; Jeffery, I.B.; Conde, S.; Power, S.E.; O'Connor, E.M.; Cusack, S.; Harris, H.M.B.; Coakley, M.; Lakshminarayanan, B.; O'Sullivan, O.; et al. Gut microbiota composition correlates with diet and health in the elderly. Nature 2012, 488, 178-184. [CrossRef]

48. Le Chatelier, E.; Nielsen, T.; Qin, J.; Prifti, E.; Hildebrand, F.; Falony, G.; Almeida, M.; Arumugam, M.; Batto, J.-M.; Kennedy, S.; et al. Richness of human gut microbiome correlates with metabolic markers. Nature 2013, 500, 541-546. [CrossRef]

49. Arora, T.; Bäckhed, F. The gut microbiota and metabolic disease: Current understanding and future perspectives. J. Intern. Med. 2016, 280, 339-349. [CrossRef]

50. Abenavoli, L.; Scarpellini, E.; Colica, C.; Boccuto, L.; Salehi, B.; Sharifi-Rad, J.; Aiello, V.; Romano, B.; De Lorenzo, A.; Izzo, A.A.; et al. Gut Microbiota and Obesity: A Role for Probiotics. Nutrients 2019, 11, 2690. [CrossRef]

51. Bezek, K.; Petelin, A.; Pražnikar, J.; Nova, E.; Redondo-Useros, N.; Marcos, A.; Pražnikar, Z.J. Obesity Measures and Dietary Parameters as Predictors of Gut Microbiota Phyla in Healthy Individuals. Nutrients 2020, 12, 2695. [CrossRef]

52. Wu, M.; Yang, S.; Wang, S.; Cao, Y.; Zhao, R.; Li, X.; Xing, Y.; Liu, L.-T. Effect of Berberine on Atherosclerosis and Gut Microbiota Modulation and Their Correlation in High-Fat Diet-Fed ApoE-/- Mice. Front. Pharmacol. 2020, 11, 223. [CrossRef] [PubMed]

53. Rajilic-Stojanovic, M.; De Vos, W.M. The first 1000 cultured species of the human gastrointestinal microbiota. FEMS Microbiol. Rev. 2014, 38, 996-1047. [CrossRef] [PubMed]

54. Vos, P.; Garrity, G.; Jones, D.; Krieg, N.R.; Ludwig, W.; Rainey, F.A.; Schleifer, K.-H.; Whitman, W. (Eds.) Bergey's Manual of Systematic Bacteriology: Volume 3: The Firmicutes; Springer Science \& Business Media: New York, NY, USA, 2010.

55. Morotomi, M.; Nagai, F.; Sakon, H.; Tanaka, R. Paraprevotella clara gen. nov., sp. nov. and Paraprevotella xylaniphila sp. nov., members of the family 'Prevotellaceae' isolated from human faeces. Int. J. Syst. Evol. Microbiol. 2009, 59, 1895-1900. [CrossRef] [PubMed]

56. Narushima, S.; Itoh, K.; Miyamoto, Y.; Park, S.-H.; Nagata, K.; Kuruma, K.; Uchida, K. Deoxycholic acid formation in gnotobiotic mice associated with human intestinal bacteria. Lipids 2006, 41, 835-843. [CrossRef] [PubMed] 
57. Fukiya, S.; Arata, M.; Kawashima, H.; Yoshida, D.; Kaneko, M.; Minamida, K.; Watanabe, J.; Ogura, Y.; Uchida, K.; Itoh, K.; et al. Conversion of cholic acid and chenodeoxycholic acid into their 7-oxo derivatives byBacteroides intestinalisAM-1 isolated from human feces. FEMS Microbiol. Lett. 2009, 293, 263-270. [CrossRef] [PubMed]

58. Kasai, C.; Sugimoto, K.; Moritani, I.; Tanaka, J.; Oya, Y.; Inoue, H.; Tameda, M.; Shiraki, K.; Ito, M.; Takei, Y.; et al. Comparison of the gut microbiota composition between obese and non-obese individuals in a Japanese population, as analyzed by terminal restriction fragment length polymorphism and next-generation sequencing. BMC Gastroenterol. 2015, 15, 1-10. [CrossRef]

59. Lopetuso, L.R.; Scaldaferri, F.; Petito, V.; Gasbarrini, A. Commensal clostridia: Leading players in the maintenance of gut homeostasis. Gut Pathog. 2013, 5, 1-23. [CrossRef]

60. Tims, S.; Derom, C.; Jonkers, D.; Vlietinck, R.; Saris, W.H.; Kleerebezem, M.; De Vos, W.M.; Zoetendal, E.G. Microbiota conservation and BMI signatures in adult monozygotic twins. ISME J. 2013, 7, 707-717. [CrossRef]

61. Yanling, H.; Youfang, D.; Yanquan, L. Two Cellulolytic Clostridium Species: Clostridium cellulosi sp. nov. and Clostridium cellulofermentans sp. nov. Int. J. Syst. Bacteriol. 1991, 41, 306-309. [CrossRef]

62. Turnbaugh, P.J.; Ridaura, V.K.; Faith, J.J.; Rey, F.E.; Knight, R.; Gordon, J.I. The Effect of Diet on the Human Gut Microbiome: A Metagenomic Analysis in Humanized Gnotobiotic Mice. Sci. Transl. Med. 2009, 1, 6ra14. [CrossRef]

63. Finucane, M.M.; Sharpton, T.J.; Laurent, T.J.; Pollard, K.S. A Taxonomic Signature of Obesity in the Microbiome? Getting to the Guts of the Matter. PLoS ONE 2014, 9, e84689. [CrossRef] [PubMed]

64. Magne, F.; Gotteland, M.; Gauthier, L.; Zazueta, A.; Pesoa, S.; Navarrete, P.; Balamurugan, R. The Firmicutes/Bacteroidetes Ratio: A Relevant Marker of Gut Dysbiosis in Obese Patients? Nutrients 2020, 12, 1474. [CrossRef] [PubMed]

65. Mariat, D.; Firmesse, O.; Levenez, F.; Guimaraes, V.D.; Sokol, H.; Doré, J.; Corthier, G.; Furet, J.-P. The Firmicutes/Bacteroidetes ratio of the human microbiota changes with age. BMC Microbiol. 2009, 9, 123. [CrossRef] [PubMed]

66. Vaiserman, A.; Romanenko, M.; Piven, L.; Moseiko, V.; Lushchak, O.; Kryzhanovska, N.; Guryanov, V.; Koliada, A. Differences in the gut Firmicutes to Bacteroidetes ratio across age groups in healthy Ukrainian population. BMC Microbiol. 2020, 20, 1-8. [CrossRef] [PubMed]

67. Nicholson, J.K.; Holmes, E.; Kinross, J.; Burcelin, R.; Gibson, G.; Jia, W.; Pettersson, S. Host-Gut Microbiota Metabolic Interactions. Science 2012, 336, 1262-1267. [CrossRef]

68. Tang, W.W.H.; Kitai, T.; Hazen, S.L. Gut Microbiota in Cardiovascular Health and Disease. Circ. Res. 2017, 120, 1183-1196. [CrossRef]

69. Peter, J.; Fournier, C.; Keip, B.; Rittershaus, N.; Stephanou-Rieser, N.; Durdevic, M.; Dejaco, C.; Michalski, M.; Moser, G. Intestinal Microbiome in Irritable Bowel Syndrome before and after Gut-Directed Hypnotherapy. Int. J. Mol. Sci. 2018, 19, 3619. [CrossRef]

70. Fernandes, J.J.D.R.; Su, W.; Rahat-Rozenbloom, S.; Wolever, T.M.S.; Comelli, E.M. Adiposity, gut microbiota and faecal short chain fatty acids are linked in adult humans. Nutr. Diabetes 2014, 4, e121. [CrossRef]

71. Vrieze, A.; Van Nood, E.; Holleman, F.; Salojärvi, J.; Kootte, R.S.; Bartelsman, J.F.W.M.; Dallinga-Thie, G.M.; Ackermans, M.T.; Serlie, M.J.; Oozeer, R.; et al. Transfer of Intestinal Microbiota From Lean Donors Increases Insulin Sensitivity in Individuals With Metabolic Syndrome. Gastroenterology 2012, 143, 913-916. [CrossRef]

72. Schwiertz, A.; Taras, D.; Schaefer, K.; Beijer, S.; Bos, N.A.; Donus, C.; Hardt, P.D. Microbiota and SCFA in Lean and Overweight Healthy Subjects. Obesity 2010, 18, 190-195. [CrossRef]

73. Duncan, S.H.; E Lobley, G.; Holtrop, G.; Ince, J.; Johnstone, A.M.; Louis, P.; Flint, H.J. Human colonic microbiota associated with diet, obesity and weight loss. Int. J. Obes. 2008, 32, 1720-1724. [CrossRef] [PubMed]

74. Andoh, A.; Nishida, A.; Takahashi, K.; Inatomi, O.; Imaeda, H.; Bamba, S.; Kito, K.; Sugimoto, M.; Kobayashi, T. Comparison of the gut microbial community between obese and lean peoples using $16 \mathrm{~S}$ gene sequencing in a Japanese population. J. Clin. Biochem. Nutr. 2016, 59, 65-70. [CrossRef] [PubMed]

75. Payne, A.N.; Chassard, C.; Zimmermann, M.B.; Muller, P.H.; Stinca, S.; Lacroix, C. The metabolic activity of gut microbiota in obese children is increased compared with normal-weight children and exhibits more exhaustive substrate utilization. Nutr. Diabetes 2011, 1, e12. [CrossRef] [PubMed]

76. Angelakis, E.; Armougom, F.; Million, M.; Raoult, D. The relationship between gut microbiota and weight gain in humans. Future Microbiol. 2012, 7, 91-109. [CrossRef] [PubMed]

77. Walters, W.A.; Xu, Z.; Knight, R. Meta-analyses of human gut microbes associated with obesity and IBD. FEBS Lett. 2014, 588, 4223-4233. [CrossRef] [PubMed]

78. Harris, K.; Kassis, A.; Major, G.; Chou, C.J. Is the Gut Microbiota a New Factor Contributing to Obesity and Its Metabolic Disorders? J. Obes. 2012, 2012, 1-14. [CrossRef]

79. Saltykova, I.V.; Petrov, V.A.; Logacheva, M.D.; Ivanova, P.G.; Merzlikin, N.V.; Sazonov, A.E.; Ogorodova, L.; Brindley, P.J. Biliary Microbiota, Gallstone Disease and Infection with Opisthorchis felineus. PLoS Negl. Trop. Dis. 2016, 10, e0004809. [CrossRef]

80. Ren, X.; Xu, J.; Zhang, Y.; Chen, G.; Zhang, Y.; Huang, Q.; Liu, Y. Bacterial Alterations in Post-Cholecystectomy Patients Are Associated With Colorectal Cancer. Front. Oncol. 2020, 10, 1418. [CrossRef]

81. Wang, W.; Wang, J.; Li, J.; Yan, P.; Jin, Y.; Zhang, R.; Yue, W.; Guo, Q.; Geng, J. Cholecystectomy Damages Aging-Associated Intestinal Microbiota Construction. Front. Microbiol. 2018, 9, 1402. [CrossRef]

82. Yoon, W.J.; Kim, H.-N.; Park, E.; Ryu, S.; Chang, Y.; Shin, H.; Kim, H.-L.; Yi, S.Y. The Impact of Cholecystectomy on the Gut Microbiota: A Case-Control Study. J. Clin. Med. 2019, 8, 79. [CrossRef] 
83. Qin, J.; Li, Y.; Cai, Z.; Li, S.; Zhu, J.; Zhang, F.; Liang, S.; Zhang, W.; Guan, Y.; Shen, D.; et al. A metagenome-wide association study of gut microbiota in type 2 diabetes. Nature 2012, 490, 55-60. [CrossRef] [PubMed]

84. Gutiérrez-Díaz, I.; Molinero, N.; Cabrera, A.; Rodríguez, J.I.; Margolles, A.; Delgado, S.; González, S. Diet: Cause or Consequence of the Microbial Profile of Cholelithiasis Disease? Nutrients 2018, 10, 1307. [CrossRef] [PubMed]

85. Del Chierico, F.; Nobili, V.; Vernocchi, P.; Russo, A.; De Stefanis, C.; Gnani, D.; Furlanello, C.; Zandonà, A.; Paci, P.; Capuani, G.; et al. Gut microbiota profiling of pediatric nonalcoholic fatty liver disease and obese patients unveiled by an integrated meta-omics-based approach. Hepatology 2017, 65, 451-464. [CrossRef] [PubMed]

86. Zhu, L.; Baker, S.S.; Gill, C.; Liu, W.; Alkhouri, R.; Baker, R.D.; Gill, S.R. Characterization of gut microbiomes in nonalcoholic steatohepatitis (NASH) patients: A connection between endogenous alcohol and NASH. Hepatology 2013, 57, 601-609. [CrossRef]

87. Wong, V.W.-S.; Tse, C.-H.; Lam, T.T.-Y.; Wong, G.L.-H.; Chim, A.M.-L.; Chu, W.C.-W.; Yeung, D.K.-W.; Law, P.T.-W.; Kwan, H.-S.; $\mathrm{Yu}$, J.; et al. Molecular Characterization of the Fecal Microbiota in Patients with Nonalcoholic Steatohepatitis-A Longitudinal Study. PLoS ONE 2013, 8, e62885. [CrossRef]

88. Da Silva, H.E.; Teterina, A.; Comelli, E.M.; Taibi, A.; Arendt, B.M.; Fischer, S.E.; Lou, W.; Allard, J.P. Nonalcoholic fatty liver disease is associated with dysbiosis independent of body mass index and insulin resistance. Sci. Rep. 2018, 8, 1-12. [CrossRef]

89. Cortés-Martín, A.; Iglesias-Aguirre, C.E.; Meoro, A.; Selma, M.V.; Espín, J.C. There is No Distinctive Gut Microbiota Signature in the Metabolic Syndrome: Contribution of Cardiovascular Disease Risk Factors and Associated Medication. Microorganisms 2020, 8, 416. [CrossRef]

90. Álvarez-Mercado, A.I.; Navarro-Oliveros, M.; Robles-Sánchez, C.; Plaza-Díaz, J.; Sáez-Lara, M.J.; Muñoz-Quezada, S.; Fontana, L.; Abadía-Molina, F. Microbial Population Changes and Their Relationship with Human Health and Disease. Microorganisms 2019, 7, 68. [CrossRef]

91. Evans, C.C.; LePard, K.J.; Kwak, J.W.; Stancukas, M.C.; Laskowski, S.; Dougherty, J.; Moulton, L.; Glawe, A.; Wang, Y.; Leone, V.; et al. Exercise Prevents Weight Gain and Alters the Gut Microbiota in a Mouse Model of High Fat Diet-Induced Obesity. PLoS ONE 2014, 9, e92193. [CrossRef]

92. Maki, T. Pathogenesis of calcium bilirubinate gallstone: Role of E. coli, beta-glucuronidase and coagulation by inorganic ions, polyelectrolytes and agitation. Ann. Surg. 2006, 164, 90-100. [CrossRef]

93. Stewart, L.; Smith, A.L.; Pellegrini, C.A.; Motson, R.W.; Way, L.W. Pigment Gallstones Form as a Composite of Bacterial Microcolonies and Pigment Solids. Ann. Surg. 1987, 206, 242-250. [CrossRef] [PubMed]

94. Ridlon, J.M.; Kang, D.-J.; Hylemon, P.B. Bile salt biotransformations by human intestinal bacteria. J. Lipid Res. 2005, 47, 241-259. [CrossRef] [PubMed]

95. Gérard, P. Metabolism of Cholesterol and Bile Acids by the Gut Microbiota. Pathogens 2013, 3, 14-24. [CrossRef] [PubMed]

96. Ridlon, J.M.; Harris, S.C.; Bhowmik, S.; Kang, D.-J.; Hylemon, P.B. Consequences of bile salt biotransformations by intestinal bacteria. Gut Microbes 2016, 7, 22-39. [CrossRef] [PubMed]

97. Long, S.L.; Gahan, C.G.M.; Joyce, S.A. Interactions between gut bacteria and bile in health and disease. Mol. Asp. Med. 2017, 56, 54-65. [CrossRef]

98. Li, F.; Jiang, C.; Krausz, K.W.; Li, Y.; Albert, I.; Hao, H.; Fabre, K.M.; Mitchell, J.B.; Patterson, A.D.; Gonzalez, F.J. Microbiome remodelling leads to inhibition of intestinal farnesoid $X$ receptor signalling and decreased obesity. Nat. Commun. 2013, 4, 1-10. [CrossRef]

99. Wells, J.E.; Berr, F.; Thomas, L.A.; Dowling, R.; Hylemon, P.B. Isolation and characterization of cholic acid $7 \alpha$-dehydroxylating fecal bacteria from cholesterol gallstone patients. J. Hepatol. 2000, 32, 4-10. [CrossRef]

100. Berr, F.; Kullak-Ublick, G.A.; Paumgartner, G.; Munzing, W.; Hylemon, P.B. 7 alpha-dehydroxylating bacteria enhance deoxycholic acid input and cholesterol saturation of bile in patients with gallstones. Gastroenterology 1996, 111, 1611-1620. [CrossRef]

101. Hussaini, S.H.; Pereira, S.P.; Murphy, G.M.; Dowling, R.H. Deoxycholic acid influences cholesterol solubilization and microcrystal nucleation time in gallbladder bile. Hepatology 1995, 22, 1735-1744.

102. Fremont-Rahl, J.J.; Ge, Z.; Umana, C.; Whary, M.T.; Taylor, N.S.; Muthupalani, S.; Carey, M.C.; Fox, J.G.; Maurer, K.J. An Analysis of the Role of the Indigenous Microbiota in Cholesterol Gallstone Pathogenesis. PLoS ONE 2013, 8, e70657. [CrossRef]

103. Wang, Q.; Jiao, L.; He, C.; Sun, H.; Cai, Q.; Han, T.; Hu, H. Alteration of gut microbiota in association with cholesterol gallstone formation in mice. BMC Gastroenterol. 2017, 17, 1-9. [CrossRef] [PubMed]

104. Grigor'eva, I.N.; Romanova, T.I. Gallstone Disease and Microbiome. Microorganisms 2020, 8, 835. [CrossRef] [PubMed]

105. Hepner, G.W.; Hofmann, A.F.; Malagelada, J.R.; Szczepanik, P.A.; Klein, P.D. Increased Bacterial Degradation of Bile Acids in Cholecystectomized Patients. Gastroenterology 1974, 66, 556-564. [CrossRef]

106. Kang, Z.; Lu, M.; Jiang, M.; Zhou, D.; Huang, H. Proteobacteria Acts as a Pathogenic Risk-Factor for Chronic Abdominal Pain and Diarrhea in Post-Cholecystectomy Syndrome Patients: A Gut Microbiome Metabolomics Study. Med. Sci. Monit. 2019, 25, 7312-7320. [CrossRef]

107. Wu, T.; Zhang, Z.; Liu, B.; Hou, D.; Liang, Y.; Zhang, J.; Shi, P. Gut microbiota dysbiosis and bacterial community assembly associated with cholesterol gallstones in large-scale study. BMC Genom. 2013, 14, 669. [CrossRef]

108. Shen, H.; Ye, F.; Xie, L.; Yang, J.; Li, Z.; Xu, P.; Meng, F.; Li, L.; Xiaochen, B.; Bo, X.; et al. Metagenomic sequencing of bile from gallstone patients to identify different microbial community patterns and novel biliary bacteria. Sci. Rep. 2015, 5, 17450. [CrossRef] 
109. Molinero, N.; Ruiz, L.; Milani, C.; Gutiérrez-Díaz, I.; Sánchez, B.; Mangifesta, M.; Segura, J.; Cambero, I.; Campelo, A.B.; García-Bernardo, C.M.; et al. The human gallbladder microbiome is related to the physiological state and the biliary metabolic profile. Microbiome 2019, 7, 1-17. [CrossRef]

110. Petrov, V.A.; Fernández-Peralbo, M.A.; Derks, R.; Knyazeva, E.M.; Merzlikin, N.V.; Sazonov, A.E.; Mayboroda, O.A.; Saltykova, I.V. Biliary Microbiota and Bile Acid Composition in Cholelithiasis. BioMed Res. Int. 2020, 2020, 1-8. [CrossRef]

111. Chen, B.; Fu, S.W.; Lu, L.-G.; Zhao, H. A Preliminary Study of Biliary Microbiota in Patients with Bile Duct Stones or Distal Cholangiocarcinoma. BioMed Res. Int. 2019, 2019, 1-12. [CrossRef]

112. Liang, T.; Su, W.; Zhang, Q.; Li, G.; Gao, S.; Lou, J.; Zhang, Y.; Ma, T.; Bai, X. Roles of Sphincter of Oddi Laxity in Bile Duct Microenvironment in Patients with Cholangiolithiasis: From the Perspective of the Microbiome and Metabolome. J. Am. Coll. Surg. 2016, 222, 269-280. [CrossRef]

113. Tsuchiya, Y.; Loza, E.; Villa-Gomez, G.; Trujillo, C.C.; Baez, S.; Asai, T.; Ikoma, T.; Endoh, K.; Nakamura, K. Metagenomics of Microbial Communities in Gallbladder Bile from Patients with Gallbladder Cancer or Cholelithiasis. Asian Pac. J. Cancer Prev. 2018, 19, 961-967. [PubMed]

114. Capoor, M.R.; Nair, D.; Rajni; Khanna, G.; Krishna, S.V.; Chintamani, M.S.; Aggarwal, P. Microflora of bile aspirates in patients with acute cholecystitis with or without cholelithiasis: A tropical experience. Braz. J. Infect. Dis. 2008, 12, 222-225. [CrossRef] [PubMed]

115. Abeysuriya, V.; Deen, K.I.; Wijesuriya, T.; Salgado, S.S. Microbiology of gallbladder bile in uncomplicated symptomatic cholelithiasis. Hepatobiliary Pancreat. Dis. Int. 2008, 7, 633-637. [PubMed]

116. Liu, J.; Yan, Q.; Luo, F.; Shang, D.; Wu, D.; Zhang, H.; Shang, X.; Kang, X.; Abdo, M.; Liu, B.; et al. Acute cholecystitis associated with infection of Enterobacteriaceae from gut microbiota. Clin. Microbiol. Infect. 2015, 21, 851.e1-851.e9. [CrossRef]

117. Ye, F.; Shen, H.; Li, Z.; Meng, F.; Li, L.; Yang, J.; Chen, Y.; Bo, X.; Zhang, X.; Ni, M. Influence of the Biliary System on Biliary Bacteria Revealed by Bacterial Communities of the Human Biliary and Upper Digestive Tracts. PLoS ONE 2016, 11, e0150519. [CrossRef]

118. Song, X.; Wang, X.; Hu, Y.; Li, H.; Ren, T.; Li, Y.; Liu, L.; Li, L.; Li, X.; Wang, Z.; et al. A metagenomic study of biliary microbiome change along the cholecystitis-carcinoma sequence. Clin. Transl. Med. 2020, 10, 97. [CrossRef]

119. Kujiraoka, M.; Kuroda, M.; Asai, K.; Sekizuka, T.; Kato, K.; Watanabe, M.; Matsukiyo, H.; Saito, T.; Ishii, T.; Katada, N.; et al. Comprehensive Diagnosis of Bacterial Infection Associated with Acute Cholecystitis Using Metagenomic Approach. Front. Microbiol. 2017, 8, 685. [CrossRef]

120. Islam, K.S.; Fukiya, S.; Hagio, M.; Fujii, N.; Ishizuka, S.; Ooka, T.; Ogura, Y.; Hayashi, T.; Yokota, A. Bile Acid Is a Host Factor That Regulates the Composition of the Cecal Microbiota in Rats. Gastroenterology 2011, 141, 1773-1781. [CrossRef]

121. Ridlon, J.M.; Alves, J.M.P.; Hylemon, P.B.; Bajaj, J.S. Cirrhosis, bile acids and gut microbiota: Unraveling a complex relationship. Gut Microbes 2013, 4, 382-387. [CrossRef]

122. Tajeddin, E.; Sherafat, S.J.; Majidi, M.R.S.; Alebouyeh, M.; Alizadeh, A.H.M.; Zali, M.R. Association of diverse bacterial communities in human bile samples with biliary tract disorders: A survey using culture and polymerase chain reaction-denaturing gradient gel electrophoresis methods. Eur. J. Clin. Microbiol. Infect. Dis. 2016, 35, 1331-1339. [CrossRef]

123. Anhê, F.F.; Jensen, B.A.H.; Varin, T.V.; Servant, F.; Van Blerk, S.; Richard, D.; Marceau, S.; Surette, M.G.; Biertho, L.; Lelouvier, B.; et al. Type 2 diabetes influences bacterial tissue compartmentalisation in human obesity. Nat. Metab. 2020, 2, 233-242. [CrossRef] [PubMed]

124. Massier, L.; Chakaroun, R.; Tabei, S.; Crane, A.; Didt, K.D.; Fallmann, J.; Von Bergen, M.; Haange, S.-B.; Heyne, H.; Stumvoll, M.; et al. Adipose tissue derived bacteria are associated with inflammation in obesity and type 2 diabetes. Gut 2020, 69, $1796-1806$. [CrossRef] [PubMed]

125. Mouzaki, M.; Comelli, E.M.; Arendt, B.M.; Bonengel, J.; Fung, S.K.; Fischer, S.E.; McGilvray, I.D.; Allard, J.P. Intestinal microbiota in patients with nonalcoholic fatty liver disease. Hepatology 2013, 58, 120-127. [CrossRef] [PubMed]

126. Raman, M.; Ahmed, I.; Gillevet, P.M.; Probert, C.S.; Ratcliffe, N.M.; Smith, S.; Greenwood, R.; Sikaroodi, M.; Lam, V.; Crotty, P.; et al. Fecal Microbiome and Volatile Organic Compound Metabolome in Obese Humans With Nonalcoholic Fatty Liver Disease. Clin. Gastroenterol. Hepatol. 2013, 11, 868-875.e3. [CrossRef] [PubMed]

127. Mueller, S.; Saunier, K.; Hanisch, C.; Norin, E.; Alm, L.; Midtvedt, T.; Cresci, A.; Silvi, S.; Orpianesi, C.; Verdenelli, M.C.; et al. Differences in Fecal Microbiota in Different European Study Populations in Relation to Age, Gender, and Country: A Cross-Sectional Study. Appl. Environ. Microbiol. 2006, 72, 1027-1033. [CrossRef] [PubMed]

128. Haro, C.; Rangel-Zúñiga, O.A.; Alcalá-Díaz, J.F.; Gómez-Delgado, F.; Pérez-Martínez, P.; Delgado-Lista, J.; Quintana-Navarro, G.M.; Landa, B.B.; Cortés, J.A.N.; Tena-Sempere, M.; et al. Intestinal Microbiota Is Influenced by Gender and Body Mass Index. PLoS ONE 2016, 11, e0154090. [CrossRef]

129. Rinninella, E.; Raoul, P.; Cintoni, M.; Franceschi, F.; Miggiano, G.A.D.; Gasbarrini, A.; Mele, M.C. What is the Healthy Gut Microbiota Composition? A Changing Ecosystem across Age, Environment, Diet, and Diseases. Microorganisms 2019, 7, 14. [CrossRef]

130. Wu, G.D.; Chen, J.; Hoffmann, C.; Bittinger, K.; Chen, Y.-Y.; Keilbaugh, S.A.; Bewtra, M.; Knights, D.; Walters, W.A.; Knight, R.; et al. Linking Long-Term Dietary Patterns with Gut Microbial Enterotypes. Science 2011, 334, 105-108. [CrossRef]

131. Clarke, S.F.; Murphy, E.F.; O'Sullivan, O.; Lucey, A.J.; Humphreys, M.; Hogan, A.; Hayes, P.; O'Reilly, M.; Jeffery, I.B.; Wood-Martin, R.; et al. Exercise and associated dietary extremes impact on gut microbial diversity. Gut 2014, 63, 1913-1920. [CrossRef] 
132. Friedman, G.D.; Kannel, W.B.; Dawber, T.R. The epidemiology of gallbladder disease: Observations in the Framingham study. J. Chronic Dis. 2004, 19, 273-292. [CrossRef]

133. Wirth, J.; Song, M.; Fung, T.T.; Joshi, A.D.T.; Tabung, F.K.; Chan, A.T.; Weikert, C.; Leitzmann, M.; Willett, W.C.; Giovannucci, E.; et al. Diet-quality scores and the risk of symptomatic gallstone disease: A prospective cohort study of male US health professionals. Int. J. Epidemiol. 2018, 47, 1938-1946. [CrossRef] [PubMed]

134. Park, Y.; Kim, D.; Lee, J.S.; Na Kim, Y.; Jung, Y.K.; Lee, K.G.; Choi, D. Association between diet and gallstones of cholesterol and pigment among patients with cholecystectomy: A case-control study in Korea. J. Health Popul. Nutr. 2017, 36, 39. [CrossRef] [PubMed]

135. Attili, A.F.; Scafato, E.; Marchioli, R.; Marfisi, R.M.; Festi, D. The MICOL Group Diet and gallstones in Italy: The cross-sectional MICOL results. Hepatology 1998, 27, 1492-1498. [CrossRef] [PubMed]

136. Walther, B.; Lett, A.M.; Bordoni, A.; Tomás-Cobos, L.; Nieto, J.A.; Dupont, D.; Danesi, F.; Shahar, D.R.; Echaniz, A.; Re, R.; et al. GutSelf: Interindividual Variability in the Processing of Dietary Compounds by the Human Gastrointestinal Tract. Mol. Nutr. Food Res. 2019, 63, e1900677. [CrossRef] [PubMed]

137. Modi, S.R.; Collins, J.J.; Relman, D.A. Antibiotics and the gut microbiota. J. Clin. Investig. 2014, 124, 4212-4218. [CrossRef] [PubMed]

138. De La Cuesta-Zuluaga, J.; Mueller, N.T.; Corrales-Agudelo, V.; Velásquez-Mejía, E.P.; Carmona, J.A.; Abad, J.M.; Escobar, J.S. Metformin Is Associated With Higher Relative Abundance of Mucin-DegradingAkkermansia muciniphilaand Several Short-Chain Fatty Acid-Producing Microbiota in the Gut. Diabetes Care 2017, 40, 54-62. [CrossRef]

139. Suzuki, T.A.; Worobey, M. Geographical variation of human gut microbial composition. Biol. Lett. 2014, 10, 20131037. [CrossRef]

140. David, L.A.; Materna, A.C.; Friedman, J.; Campos-Baptista, M.I.; Blackburn, M.C.; Perrotta, A.; Erdman, S.E.; Alm, E.J. Host lifestyle affects human microbiota on daily timescales. Genome Biol. 2014, 15. [CrossRef]

141. Tyakht, A.V.; Kostryukova, E.S.; Popenko, A.S.; Belenikin, M.S.; Pavlenko, A.V.; Larin, A.K.; Karpova, I.Y.; Selezneva, O.V.; Semashko, T.A.; Ospanova, E.A.; et al. Human gut microbiota community structures in urban and rural populations in Russia. Nat. Commun. 2013, 4, 2469. [CrossRef]

142. Benedict, C.; Vogel, H.; Jonas, W.; Woting, A.; Blaut, M.; Schuermann, A.; Cedernaes, J. Gut microbiota and glucometabolic alterations in response to recurrent partial sleep deprivation in normal-weight young individuals. Mol. Metab. 2016, 5, 1175-1186. [CrossRef]

143. Thaiss, C.A.; Zeevi, D.; Levy, M.; Zilberman-Schapira, G.; Suez, J.; Tengeler, A.C.; Abramson, L.; Katz, M.N.; Korem, T.; Zmora, N.; et al. Transkingdom Control of Microbiota Diurnal Oscillations Promotes Metabolic Homeostasis. Cell 2014, 159, 514-529. [CrossRef] [PubMed]

144. Sze, M.A.; Schloss, P.D. Looking for a Signal in the Noise: Revisiting Obesity and the Microbiome. MBio 2016, 7 . [CrossRef] [PubMed]

145. Wesolowska-Andersen, A.; Bahl, M.I.; Carvalho, V.; Kristiansen, K.; Sicheritz-Pontén, T.; Gupta, R.; Licht, T.R. Choice of bacterial DNA extraction method from fecal material influences community structure as evaluated by metagenomic analysis. Microbiome 2014, 2, 19. [CrossRef] [PubMed]

146. Lozupone, C.A.; Stombaugh, J.; Gonzalez, A.; Ackermann, G.; Wendel, D.; Vázquez-Baeza, Y.; Jansson, J.K.; Gordon, J.I.; Knight, R. Meta-analyses of studies of the human microbiota. Genome Res. 2013, 23, 1704-1714. [CrossRef]

147. Faith, J.J.; Guruge, J.L.; Charbonneau, M.; Subramanian, S.; Seedorf, H.; Goodman, A.L.; Clemente, J.C.; Knight, R.; Heath, A.C.; Leibel, R.L.; et al. The Long-Term Stability of the Human Gut Microbiota. Science 2013, 341, 1237439. [CrossRef]

148. Mahowald, M.A.; Rey, F.E.; Seedorf, H.; Turnbaugh, P.J.; Fulton, R.S.; Wollam, A.; Shah, N.; Wang, C.; Magrini, V.; Wilson, R.K.; et al. Characterizing a model human gut microbiota composed of members of its two dominant bacterial phyla. Proc. Natl. Acad. Sci. USA 2009, 106, 5859-5864. [CrossRef]

149. Samuel, B.S.; Gordon, J.I. A humanized gnotobiotic mouse model of host-archaeal-bacterial mutualism. Proc. Natl. Acad. Sci. USA 2006, 103, 10011-10016. [CrossRef]

150. Jayasinghe, T.N.; Chiavaroli, V.; Holland, D.J.; Cutfield, W.S.; O'Sullivan, J.M. The New Era of Treatment for Obesity and Metabolic Disorders: Evidence and Expectations for Gut Microbiome Transplantation. Front. Cell. Infect. Microbiol. $2016,6,15$. [CrossRef] 